\title{
Elaboração e análise comparativa do índice de qualidade ambiental em núcleos
}

\section{urbanos}

Elaboration and comparative analysis of the environmental quality index in urban centers

Elaboración y análisis comparativo del índice de calidad ambiental en centros urbanos

Recebido: 06/08/2021 | Revisado: 11/08/2021 | Aceito: 15/08/2021 | Publicado: 17/08/2021

\author{
Arthur Gabriel Lopes Leal \\ ORCID: http://orcid.org/0000-0002-3410-9253 \\ Universidade do Estado do Pará, Brasil \\ E-mail: arthurgleal@hotmail.com \\ Yuri Araújo Carréra \\ ORCID: http://orcid.org/0000-0003-1492-7272 \\ Universidade do Estado do Pará, Brasil \\ E-mail: yuri.carreraa@gmail.com \\ Antônio Pereira Junior \\ ORCID: http://orcid.org/0000-0001-6241-985X \\ Universidade do Estado do Pará, Brasil \\ E-mail: antonio.junior@uepa.br
}

\begin{abstract}
Resumo
A construção de um Índice de Qualidade Ambiental Urbana (IQAU), é uma tarefa complexa, a qual varia e se combina continuamente sobre a paisagem urbana em diversas escalas de análise. O objetivo foi efetuar um comparativo entre núcleos urbanos sobre a qualidade ambiental, além de verificar a percepção ambiental da comunidade com relação a qualidade de vida urbana e, por fim, propor duas medidas mitigatórias para cada indicador adotado. A pesquisa foi realizada na cidade de Marabá, nos núcleos Cidade Nova (Novo Horizonte) e Nova Marabá (Folha 22). Nos dados primários realizou-se a aplicação de 208 formulários simples, composto por perguntas objetivas e adoção de notas de 0 a 10 para cada indicador ambiental que compuseram esse índice. Quanto aos dados secundários, foi efetuado um levantamento de dados documentais, com o intuito de agregar conhecimento sobre os indicadores usados na pesquisa, bem como, a correlação quanto a qualidade de vida urbana, para identificar se tais indicadores são relevantes para avaliar a qualidade dos ambientes escolhidos na pesquisa, para isso foi usado um recorte temporal situado entre os anos de 2009 e 2018. Os dados obtidos e analisados indicam que o núcleo Nova Marabá (IQAU = 47,96) obteve classificação "ruim". O núcleo Cidade Nova (IQAU = 63,17), essa $(+15,21)$, o que comprovou a influência que um planejamento urbano tem sobre a qualidade ambiental foi identificada como "intermediária". O fator determinante para as classificações com base nas quantificações, foi o planejamento urbano adotado no Cidade Nova, o que não foi identificado na NB. Com isso, verificou-se que o planejamento urbano em núcleos dos municípios pode melhorar o IQAU, e a saúde dos munícipes.
\end{abstract}

Palavras-chave: Indicadores ambientais; Percepção ambiental; Planejamento urbano.

\begin{abstract}
The construction of an Urban Environmental Quality Index (UQI) is a complex task, which varies and combines continuously over the urban landscape in several scales of analysis. The objective was to make a comparison between urban centers on environmental quality, besides verifying the environmental perception of the community regarding the quality of urban life and, finally, to propose two mitigating measures for each indicator adopted. The research was carried out in the city of Marabá, in the cores Cidade Nova (Novo Horizonte) and Nova Marabá (Folha 22). For the primary data, 208 simple forms were applied, composed of objective questions and the adoption of scores from 0 to 10 for each environmental indicator that composed the IQAU. As for the secondary data, a survey of documentary data was carried out to add knowledge about the indicators used in the research, as well as the correlation regarding the quality of urban life, to identify whether such indicators are relevant to assess the quality of the environments chosen in the research, for this, a time frame between the years 2009 to 2018 was used. The data obtained and analyzed indicate that the Nova Marabá core (IQAU = 47.96) obtained a "bad" classification. The core Cidade Nova (IQAU $=63.17)$, this $(+15.21)$, which proved the influence that an urban planning has on environmental quality was identified as "intermediate". The determining factor for the classifications based on the quantifications, was the urban planning adopted in Cidade Nova, which was not identified in the NB. With this, it was verified that urban planning in cores of the municipalities can improve the IQAU, and the health of the municipalities' residents.
\end{abstract}

Keywords: Environmental indicators; Environmental perception; Urban planning. 


\begin{abstract}
Resumen
La construcción de un Índice de Calidad Ambiental Urbana (ICU), es una tarea compleja, que varía y se combina continuamente en el paisaje urbano en varias escalas de análisis. El objetivo fue hacer una comparación entre los centros urbanos sobre la calidad ambiental, además de verificar la percepción ambiental de la comunidad respecto a la calidad de vida urbana $\mathrm{y}$, finalmente, proponer dos medidas mitigadoras para cada indicador adoptado. La investigación se realizó en la ciudad de Marabá, en los núcleos Cidade Nova (Novo Horizonte) y Nova Marabá (Hoja 22). En los datos primarios se aplicaron 208 formularios sencillos, compuestos por preguntas objetivas y adopción de puntuaciones de 0 a 10 para cada uno de los indicadores ambientales que componen el IQAU. En cuanto a los datos secundarios, se realizó un levantamiento de datos documentales, con el fin de agregar conocimiento sobre los indicadores utilizados en la investigación, así como la correlación respecto a la calidad de vida urbana, para identificar si dichos indicadores son relevantes para evaluar la calidad de los entornos elegidos en la investigación, para ello se utilizó un corte temporal situado entre los años 2009 y 2018. Los datos obtenidos y analizados indican que el núcleo Nova Marabá (IQAU = 47,96) obtuvo una clasificación "mala". El núcleo de Cidade Nova (IQAU = 63,17), esta $(+15,21)$, lo que demostró la influencia que tiene una planificación urbana en la calidad ambiental fue identificado como "intermedio". El factor determinante para las clasificaciones basadas en las cuantificaciones fue la planificación urbana adoptada en Cidade Nova, que no fue identificada en el NB. Con esto, se comprobó que la planificación urbana en los núcleos de los municipios puede mejorar el IQAU, y la salud de los habitantes de los municipios.
\end{abstract}

Palabras clave: Indicadores ambientales; Percepción ambiental; Planificación urbana.

\title{
1. Introdução
}

A qualidade ambiental urbana é definida como a capacidade das políticas urbanas se adaptarem à oferta de serviços, à qualidade e à quantidade das demandas sociais, com o intuito de buscar o equilíbrio entre as demandas de serviços urbanos e investimentos em estrutura. A Lei Federal n. ${ }^{\circ} 10.257$ (2001), também conhecida por Estatuto da Cidade, e talvez a mais importante na atualidade em se tratando do planejamento urbano, estabelece diretrizes para o uso da propriedade urbana em prol do bem coletivo, da segurança e do bem-estar dos cidadãos, bem como do equilíbrio ambiental (BRASIL, 2001).

Nesse sentido, a elaboração de um Índice de Qualidade Ambiental Urbana (IQAU), é uma tarefa complexa, uma vez que ele é obtido em função de muitos parâmetros que atuam sinergicamente como, por exemplo, coleta de resíduos urbanos. Todavia, eles sofrem variações e combinações de forma contínua na paisagem urbana em diversas escalas de análise (Lima, 2013). Em vista disso, para compor um IQAU faz-se necessário a utilização de indicadores, concisos e fáceis de serem interpretados, e que, comumente são utilizados para ilustrar as principais características de uma determinada região (Fornazieiro, 2020).

Acerca desses indicadores, no município de Altamira, para o bairro Jardim Independente I, foram aplicados cinco indicadores: abastecimento de água, esgotamento sanitário, limpeza pública urbana, pavimentação de vias, e cobertura vegetal. Todos eles refletiram as principais e mais perceptíveis características físicas e de infraestrutura daquela localidade (Teixeira et al., 2019).

Um dos fatores que interferem no abastecimento da água, é a qualidade dela, que pode ser comprometida com o esgotamento das águas superficiais e a drenagem, extremamente necessárias quando envolve o crescimento urbano que, nos municípios brasileiros, como Paragominas e Marabá, ocorre de forma não planejada e, como resultado disso, tem-se a alteração na qualidade desse recurso natural a partir de cargas poluitiva como, por exemplo, coliformes fecais (Lima et al., 2020).

Para mensura o comprometimento ambiental, existem inúmeras ferramentas, dentre elas, a aplicação da Modelagem matemática, que permite a descrição e interpretação de dados específicos como, por exemplo, constitui uma ferramenta poderosa para a solução de problemas reais e para a fundamentação de decisões (medidas mitigadoras). Por isso, torna-se interessante envolver a matemática em questões relacionadas com o Meio Ambiente (Penereiro \& Ferreira, 2012).

Nesse contexto, os modelos matemáticos são importantes, pois imitam um fenômeno real e permitem fazer predições quantitativas. Desse modo, contribui-se para avaliar uma única fonte, à carga poluidora; analisar áreas de riscos e administrar liberações emergenciais (Rodrigues, 2013). Por esse âmbito, o comportamento da população urbana, associada a aplicabilidade justa da legislação ambiental, independente da esfera política, ou seja, federal, estadual ou municipal, determina 
o cumprimento da obrigatoriedade dessa comunidade conforme o descrito na Constituição Federal, no artigo 225, além do contido no Estatuto da Cidade, em função de outros dois artigos constitucionais: 182 e 183 (Valesí, 2014).

A matriz proposta por Leopold, em 1971, a qual apresenta caráter bidimensional simples, que relaciona as ações de um projeto a vários fatores ambientais, portanto, aplicado a esta pesquisa em virtude de ser um método quantitativo de avaliação de impacto e que permite uma rápida identificação, ainda que preliminar, dos problemas ambientais envolvidos em determinados processos (Cavalcante \& Leite, 2016).

Nesse sentido, como fruto da urbanização desenfreada, sem base de planejamento, a problemática ambiental se agrava e ganha escopo cada vez mais à medida que as cidades se expandem. A partir desse cenário, pode-se tentar compreender a importância que assume a preocupação com a qualidade ambiental urbana, vista como elemento fundamental para o alcance da melhoria da qualidade de vida do homem urbano (Belizário, 2014).

Portanto, esses argumentos justificaram este estudo e incrementaram a relevância dele, já que o objetivo foi a elaboração e a análise de forma quantitativa e qualitativa dos indicadores componentes do IQAU, quanto a percepção ambiental dos indivíduos amostrados, nos núcleos Cidade Nova e Nova Marabá, efetuar um comparativo entre ambos, e proceder da mesma forma com o IQAU. Finalmente, com base nos valores obtidos para esse índice, propor medidas mitigadoras (duas para cada indicador analisado, total de 10) para remediar as problemáticas encontradas e contribuir para a melhoria da qualidade do meio ambiente.

\section{Referencial Teórico}

\subsection{Núcleos urbanos}

Apesar das diferenças históricas, de dimensão, estilo arquitetônico, particularidades e funções, as cidades tendem a se assemelhar cada vez mais, principalmente em relação ao consumo desigual do espaço urbano, assim como na geração dos mais variados tipos de impactos socioambientais (Ferreira \& Matias, 2011). Os problemas de grande parte das cidades são a pobreza, a poluição, a desigualdade e o excesso de população, fatores que geram inúmeros outros problemas, principalmente os ligados às questões ambientais. Desse modo, surgiu a necessidade de incorporar os aspectos da natureza nos projetos e planejamento dos núcleos urbanos, no intuído de promover maior qualidade de vida aos moradores (Pereira, 2017). Ainda assim, os núcleos urbanos de países em desenvolvimento apresentam déficit quanto ao saneamento, como o abastecimento de água, coleta e tratamento de esgotos e de resíduos sólidos. Embora apresente visíveis avanços, ainda se faz presente em países como o Brasil (Gonçalves \& Guerra, 2009).

\section{2 Índice de Qualidade Ambiental}

A avaliação dos aspectos da IQAU constitui importante instrumento na definição das prioridades nos investimentos públicos, podendo ser utilizado na fase de planejamento, contemplando procedimentos mais eficazes para o reconhecimento das demandas da população. Com o uso de informações atualizadas e detalhadas sobre o ambiente urbano, relacionadas à expansão e ao adensamento urbano, às mudanças climáticas e à necessidade de proteção ambiental, facilita a gestão e manutenção do IQAU local (Adão \& Polette, 2016).

Nesse sentido, há relevância de avaliar a qualidade ambiental em áreas urbanas e verificar o grau de comprometimento ambiental dessas áreas, por meio da quantificação de indicadores ambientais, com o uso de técnicas de análise (Polette \& Lins-De-Barros, 2012). Devido essas interações econômicas, sociais, urbanas e demográficas, acarretam problemas como ocupação irregular do espaço por populações de baixa renda, especulação imobiliária, adensamento, verticalização, poluição, favelamento, entre outros. 
Desse modo, para diagnosticar a qualidade ambiental urbana com a intenção de propor melhorias, faz-se necessária a articulação entre conceitos e teorias nas diversas áreas do conhecimento científico. Assim deve-se escolher indicadores ambientais que melhor representem essa inter-relação dentre eles, os aspectos ambientais, sociais e econômicos da paisagem urbana (Lima, 2013).

\subsection{Indicadores Ambientais}

Por esse âmbito, os indicadores são ferramentas utilizadas para auxiliar no monitoramento da operacionalização do desenvolvimento sustentável. Logo, a sua principal função é fornecer informações sobre o estado das diversas dimensões (ambientais, econômicas, socioeconômicas, culturais, institucionais etc.) que compõem o desenvolvimento sustentável do sistema na sociedade (Carvalho \& Curi, 2013).

Por outro lado, o maior número de indicadores não necessariamente torna o índice de qualidade mais eficiente. $\mathrm{Na}$ verdade, o mais importante é o quanto os indicadores são eficazes para descrever a realidade, pois com poucos indicadores é possível caracterizar o local analisado de maneira satisfatória, deste modo, a introdução de novos indicadores tende a fornecer pequenas contribuições (Miranda et al., 2012).

Assim, a utilização de indicadores tem por objetivo reunir e quantificar informações para formação de um índice de qualidade ambiental. Os indicadores também têm sido utilizados como ferramenta padrão, pois, auxilia na compreensão das informações sobre fenômenos complexos, em diversos estudos nacionais e internacionais, visto que, permite verificar os impactos das ações humanas no ecossistema (Kemerich et al., 2014).

\subsubsection{Segurança Pública}

A segurança da sociedade surge como o principal requisito à garantia de direitos e ao cumprimento de deveres, estabelecidos nos ordenamentos jurídicos. Esta é considerada uma demanda social que necessita de estruturas estatais e demais organizações da sociedade para ser efetivada. Às instituições ou órgãos estatais, incumbidos de adotar ações voltadas para garantir a segurança da sociedade, denomina-se sistema de segurança pública, que constitui o eixo político estratégico da política desse sistema, ou seja, o conjunto de ações delineadas em planos e programas e implementados como forma de garantir a segurança individual e coletiva (Carvalho \& Silva, 2011).

Nesse sentido, tal segurança é utilizada como indicador ambiental pelo fato deste refletir diretamente na qualidade de vida da população. Desse modo, a segurança pública constitui a garantia que o estado oferece aos cidadãos contra todo o perigo que possa afetar a ordem pública, em prejuízo da vida, da liberdade, ou dos direitos de propriedades dos cidadãos: é a essência da missão dos policiais e deriva do campo jurídico (Lima et al., 2016).

\subsubsection{Abastecimento de Água}

Para que a água potável chegue às residências com qualidade para consumo humano, existe o sistema de abastecimento de água, definido pela Portaria n 2914 (2001) como: "instalação composta por um conjunto de obras civis, materiais e equipamentos, desde a zona de captação até as ligações prediais, destinada à produção e ao fornecimento coletivo de água potável, por meio de distribuição" (BRASIL, 2001).

O abastecimento de água é um aspecto indispensável, quando se trata de qualidade de vida urbana, uma vez que é um recurso de extrema importância, para fins como consumo humano. Este uso tem sofrido restrições significativas em função de prejuízos nos rios provenientes das ações naturais e antrópicas, as quais alteram os aspectos de qualidade e quantidade de água disponível para o uso humano, devido às atividades econômicas e falta de infraestrutura urbana (Encalada et al., 2016; Souza et al., 2014). 
Nesse sentido, a água de abastecimento público pode ser um veículo de doenças e agravos à saúde humana, caso ela não receba o devido tratamento, bem como, uma gestão adequada, para que ela mantenha seus padrões de qualidade, e proporcione uma melhor qualidade de vida para a população consumidora (Silva et al., 2016).

\subsubsection{Disposição de Efluentes (DE)}

A poluição dos corpos d'água através do esgotamento sanitário provoca a introdução de matéria e/ou energia que altera as características físicas e químicas da qualidade de água o que pode afetar a biota. A resposta dos corpos hídricos ao lançamento de despejos industriais e domésticos varia em função de suas características físicas, químicas e biológicas e da natureza das substâncias lançadas (Nagali \& Nemes, 2009).

Sob outra perspectiva, a legislativa, essa disposição deve obedecer a diretrizes específicas: Lei n. ${ }^{o} 11.445$ (2007), Resoluções CONAMA n. ${ }^{\circ}$ s 357 (2005) e 430 (2011), além da NBR ABNT n. 9.648 (1986). Nas duas resoluções estão estabelecidos os padrões e condições para que os efluentes possam ser lançados no meio ambiente. Já a NBR, quanto ao processo da disposição, contém a ordenação estrutural do sistema de coleta (rede, coletores, estações para tratamento, sistema de disposição final do efluente (Souza Filho et al., 2018).

\subsubsection{Limpeza Pública}

A limpeza pública consiste na varrição de vias, capina e coleta de lixo, tendo por finalidade promover o bem-estar para todos os habitantes, em conformidade com a Política Nacional de Resíduos Sólidos, Lei 12.305 (2010). Esta visa promover a proteção da saúde pública e qualidade ambiental, a não geração, redução, reutilização reciclagem e tratamento dos resíduos sólidos, bem como sua disposição final (Sousa et al., 2016).

No que se refere a gestão dos resíduos sólidos urbanos percebe-se a dificuldade dos países emergentes na destinação dos resíduos produzidos. O resultado disso, é o acúmulo desses, para atrair vetores, e afetam diretamente ou indiretamente a saúde humana (Saikia \& Nath, 2015). Para que tal gestão seja eficaz, deve haver à adesão da população e mudança de hábitos, como: aderir à prática de separação de resíduos e a falta de consideração com aquilo que é público e de uso comum, dos mesmos, pois nenhuma ação governamental em qualquer nível, seja municipal, estadual ou federal, terá plena eficácia se ambos não estiverem comprometidos com o meio ambiente (Fürstenau \& Fofonka, 2012).

\subsubsection{Pavimentação das Vias}

Numa estrutura de pavimento, um dos principais mecanismos da deterioração do serviço de misturas de asfalto é o dano de humidade. Estes danos referem-se à diminuição da força mecânica e durabilidade, devido principalmente à perda de adesão e coesão na presença de água. Isso pode afetar a geração de outros modos de deterioração das misturas asfálticas em serviço, como fissuras ou sulcos (Quintana et al., 2016). Por conseguinte, todos os métodos da estrutura asfáltica devem incorporar confiabilidade como uma forma de proteger o projeto contra uma série de problemas. Dentre elas, a incerteza na definição de cargas de tráfego, condições ambientais, evolução de deterioração, propriedades mecânicas e desempenho estrutural de materiais e qualidade nos processos de construção (Rodríguez et al., 2016).

\subsubsection{Qualidade ambiental urbana}

A rotina em cidades grandes é marcada pelo trânsito, adversidades relacionadas à segurança, falta de infraestrutura urbana, além de problemas ambientais referentes ao abastecimento de água, disposição de efluente, limpeza urbana, pavimentação das vias, entre outros. Com isso, a população que vive nos centros urbanos se torna vítima de males que podem 
impactar em seu bem estar. Ademais, tais problemáticas podem se agravar, em alguns casos, com o inadequado planejamento (Lima, 2014).

Nessa perspectiva, a expansão urbana, associada ao planejamento ineficaz, ocasiona a ocupação de áreas inadequadas para a moradia (invasões), além de provocar a degradação do ambiente, de forma a interferir na qualidade de vida urbana. De modo a acarretar modificações climáticas e ambientais, que geram um geossistema próprio dos centros urbanos (Salles et al., 2013)

\section{Metodologia}

\subsection{Fisiografia do município}

A pesquisa foi realizada no município de Marabá, sudeste do estado do Pará, cujas coordenadas geográficas são latitude: $05^{\circ} 22^{\prime} 07^{\prime \prime} \mathrm{S}$, longitude: $49^{\circ} 07^{\prime} 04^{\prime \prime} \mathrm{W}$, o clima é classificado como tropical, semiúmido, a hidrografia é constituída pelos rios Tocantins e Itacaiúnas pertencentes respectivamente as bacias hidrográficas do Araguaia-Tocantins e do Itacaiúnas (Pontes \& Cardoso, 2016).

Ainda assim, a cidade de Marabá, têm sua dinâmica atual condicionada por acontecimentos históricos que denotaram um contexto de mudança na estrutura produtiva local, e que passa a ser fortemente marcada pela agropecuária e extração mineral. Diante dessas mudanças, ocorre uma transformação na organização socioespacial, que gera uma ampliação descontínua em relação à expansão demográfica de áreas urbanas sem a adoção de um devido planejamento (Pechincha \& Zaidan, 2016).

\subsection{Método}

O método aplicado foi o dedutivo, pois de acordo com o sintetizado por Matias-Pereira (2016) e Pereira et al. (2018), há duas premissas verdadeiras: (1) a organização socioespacial de Marabá provoca modificações ambientais severas; (2) A qualidade ambiental e de vida da população dessa cidade fica comprometida com a carência/ausência de infraestrutura básica. Em relação a abrangência da pesquisa, ela foi quantitativa porque houve geração de dados numéricos para a composição do IQAU, e qualitativa, pois os dados numéricos permitiram adjetivar a qualidade do ambiente nas áreas analisadas.

Em relação a natureza, a pesquisa foi aplicada, pois os dados obtidos podem ser aplicados pelos gestores municipais na solução dos problemas identificados nas áreas pesquisadas. Quanto ao procedimento ele foi experimental porque houve interferência nos problemas encontrados e propostos soluções para a resolução dos mesmos (Sakamoto \& Silveira, 2014).

\section{3 Área da pesquisa}

Quanto as duas áreas objetos dessa pesquisa, uma situa-se no Núcleo Cidade Nova (CN), bairro Novo Horizonte, Área 1 (Figura 1A), cujo perímetro de aplicação dos formulários corresponde a 1,911 km. Nova Marabá (NM), Folha 22, Área 2 (Figura 1B), no qual o perímetro correspondeu a 1,648 km. 
Research, Society and Development, v. 10, n. 10, e510101019142, 2021

(CC BY 4.0) | ISSN 2525-3409 | DOI: http://dx.doi.org/10.33448/rsd-v10i10.19142

Figura 1: Localização das áreas A) Área 1; B) Área 2. Marabá, sudeste do Pará.
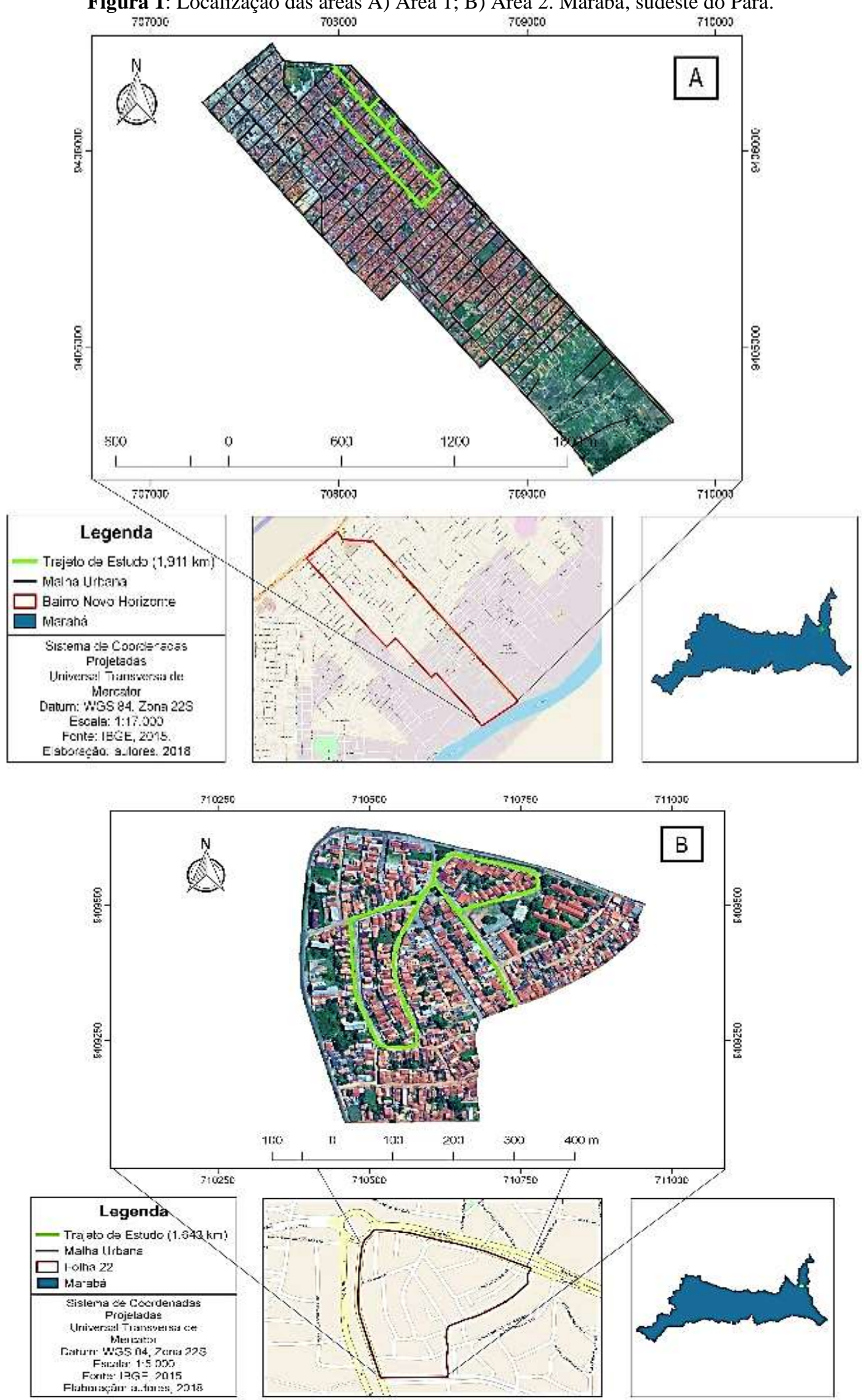

Fonte: Autores (2018). 


\subsection{Amostragem}

A obtenção dos dados primários ocorreu a partir da aplicação de 208 formulários semiestruturados (cinco questões objetivas e cinco subjetivas) acompanhados de Termo de Consentimento e Livre Esclarecimento (TCLE) em obediência as Resoluções 466 (2012) e 510 (2016), composto por perguntas objetivas acerca dos cinco indicadores previamente selecionados. Para os dados secundários, foi efetuado um Levantamento de dados documentais, cujo recorte temporal situou-se entre 2009 e 2018, cujas bases de dados foram: Google Acadêmico; Portal de Periódicos da Coordenação de Aperfeiçoamento de Pessoal de Ensino Superior (CAPES); Scientific Eletronic Library Online (SciELO); WebScience.

\subsection{Análise estatística dos dados}

Quanto aos dados estatísticos foram alocados em uma planilha eletrônica no software Excel (MICROSOFT CORPORATION, 2013), para o emprego da Estatística descritiva dos índices parciais empregou-se média ponderada. Para análise e comparação dos dados obtidos nesse município para esse tema, foi utilizada a técnica aplicada por Pereira Júnior et al. (2017), devido a similaridades do estudo e caracterizar se houve evolução ou não quanto ao tema central.

\subsection{Aplicação da matriz de Leopold}

Mediante a identificação dos indicadores ambientais listados pelo controle bidimensional (aspectos e impactos), foi possível assimilar todas as possíveis interações entre as ações e os fatores para em seguida ponderar a magnitude e a importância de cada impacto, de acordo com o preconizado por Cavalcante e Leite (2016). Os critérios e conceitos foram adaptados de estudos a partir do sintetizado por Dias et al. (2011).

\subsection{Obtenção de valores para Magnitude (M), Importância (I) e Significância (S)}

Foi adotado protocolo elaborado por Rocha (2005), onde a soma $\left(\sum\right)$ dos valores obtidos (1 a 4) nas três variáveis envolvidas tanto com a M. quanto com a I. O valor final de cada uma desses dois indicadores, novamente foram somados para a obtenção da S. (Tabela 1).

Tabela 1: ponderação dos valores para os seis atributos componentes da magnitude e importância.

\begin{tabular}{|c|c|c|c|c|c|}
\hline \multicolumn{3}{|c|}{ Magnitude (M) } & \multicolumn{3}{|c|}{ Importância (I) } \\
\hline \multirow{5}{*}{ Extensão } & Pequena extensão & +1 & \multirow{5}{*}{ Ação } & Primária & +1 \\
\hline & Média extensão & +2 & & Secundária & +2 \\
\hline & & & & & \\
\hline & Grande extensão & +3 & & Terciária & +3 \\
\hline & Muito grande extensão & +4 & & Enésima & +4 \\
\hline \multirow{3}{*}{ Periodicidade } & Ação temporária & +1 & \multirow{3}{*}{ Ignição } & Imediata & +1 \\
\hline & Ação variável & +2 & & Médio prazo & +2 \\
\hline & Ação permanente & +3 & & Longo prazo & +3 \\
\hline \multirow{3}{*}{ Intensidade } & Baixa & +1 & \multirow{3}{*}{ Criticidade } & Baixa & +1 \\
\hline & Média & +2 & & Média & +2 \\
\hline & Alta & +3 & & Alta & +3 \\
\hline
\end{tabular}

Fonte: adaptado de Rocha (2005). 
Os cálculos matemáticos foram realizados com a aplicações de três equações utilizadas para variáveis ambientais, a partir do contido em Dias et al. (2011). Os valores para a magnitude e importância, descritos por Sànchez (2013), foram empregados nos impactos ambientais avaliados nessa pesquisa (Tabela 2).

Tabela 2: Variáveis ambientais e equações aplicadas à matriz de Leopold.

\begin{tabular}{|c|c|c|c|}
\hline $\mathbf{N}^{\mathbf{o}}$ & Equação & Componentes & Valores adotados \\
\hline 1 & $M=E X T+P E R+I N T$ & $\begin{array}{l}\text { M: Magnitude; EXT: Extensão; PER: } \\
\text { Periodicidade; INT: Intensidade }\end{array}$ & $\begin{array}{c}1 \text { a } 13 \\
\left(\sum=\text { Ext }+ \text { Per+Int. }\right)\end{array}$ \\
\hline 2 & $I=A C+I G+C R$ & $\begin{array}{l}\text { I: importância; AC: ação; IG: ignição; CR: } \\
\text { criticidade. }\end{array}$ & $\begin{array}{c}1 \mathrm{a} 10 \\
\left(\sum=\mathrm{AC}+\mathrm{IG}+\mathrm{CR}\right)\end{array}$ \\
\hline 3 & $S=M A G * I M P$ & $\begin{array}{l}\text { S: significância; M: magnitude; I: } \\
\text { importância. }\end{array}$ & $\sum=\mathrm{M}+\mathrm{I}$ \\
\hline
\end{tabular}

Fonte: Autores (2020).

\subsection{Elaboração do IQAU}

Ao determinar os indicadores (Segurança pública, pavimentação das vias, abastecimento de água, disposição de efluente e limpeza pública) que serão usados para gerar o IQAU, foi adotado o protocolo de Dias et al. (2011), para o cálculo do IQAU. Assim, adotaram-se pesos que flutuam entre 15 e 25, bem como índices parciais que variam de 0 a 1 (Tabela 3).

Tabela 3: indicadores e seus respectivos pesos.

\begin{tabular}{|c|c|c|c|c|}
\hline Indicadores & Composição dos Indicadores & $\begin{array}{l}\text { Índices } \\
\text { parciais }\end{array}$ & $\begin{array}{c}\text { Peso dos } \\
\text { Indicadores }\end{array}$ & $\begin{array}{c}\text { IQAU } \\
\sum= \\
\text { SP+AA+DE+LP+ } \\
\text { PV }\end{array}$ \\
\hline $\begin{array}{c}\text { Segurança } \\
\text { pública }(\mathbf{S P})\end{array}$ & $\begin{array}{l}\text { Índice de cobertura da segurança } \\
\text { pública }(0-100 \%)\end{array}$ & $0-1$ & 20 & \\
\hline $\begin{array}{l}\text { Abastecimento de } \\
\text { água }(\mathrm{AA})\end{array}$ & Índice de cobertura da rede $(0-100 \%)$ & $0-1$ & 25 & \\
\hline $\begin{array}{l}\text { Disposição de } \\
\text { efluente (DE) }\end{array}$ & $\begin{array}{l}\text { Quantificação e classificação do modo } \\
\text { de disposição ou afastamento dos } \\
\text { esgotos }\end{array}$ & $0-1$ & 20 & 100 \\
\hline $\begin{array}{l}\text { Limpeza pública } \\
\text { (LP) }\end{array}$ & $\begin{array}{l}\text { Índice de cobertura dos serviços de } \\
\text { coleta de lixo }\end{array}$ & $0-1$ & 20 & \\
\hline $\begin{array}{c}\text { Pavimentação das } \\
\text { vias }(\mathbf{P V})\end{array}$ & $\begin{array}{l}\text { Índice de pavimentação das vias (0- } \\
100 \%)\end{array}$ & $0-1$ & 15 & \\
\hline
\end{tabular}

Fonte: adaptado de Dias e Gomes (2011).

Quanto a obtenção dos índices parciais necessários para alcançar o IQAU, foram utilizados dados obtidos a partir dos formulários aplicados in loco, os valores adotados para as notas situaram-se entre 0 e 10, com o intuito de valorar a qualidade de cada variável. Em seguida foi efetuado o cálculo da média de cada indicador. Logo após a obtenção desse valor, ele foi 
divido por 10, para obtenção do índice parcial. Finalmente, realizou-se a multiplicação do valor de cada índice pelo respectivo peso, com a finalidade de valorar cada um dos cinco indicadores.

Desse modo, foi possível obter o nível de qualidade ambiental, com a aplicação da Equação 4. Sendo que os valores se situaram entre 0 e 100 .

$$
I Q A U=(I a * P a)+(I b * P b)+(I c * P c)+(I d * P d)+(I e * P e)(4)
$$

Onde: $I Q A U$ : índice de qualidade ambiental urbana; $I$ : índice parcial; $P$ : peso do respectivo índice parcial; $a, b, c \ldots$ : indicadores parciais

Com o resultado obtido pode-se classificar o IQAU, a partir da aplicação já realizada por Dias e Gomes (2011), entre 0 e 100, e péssimo a ótimo (Tabela 4).

Tabela 4: classificação do Nível de qualidade ambiental urbana.

\begin{tabular}{ccc}
\hline Classe de IQAU & Valor do IQAU & Nível de qualidade \\
\hline A & $86-100$ & Ótimo \\
B & $66-85$ & Bom \\
C & $51-65$ & Intermediário \\
D & $26-50$ & Ruim \\
E & $0-25$ & Péssimo \\
\hline
\end{tabular}

Fonte: adaptado de Dias e Gomes (2011).

Vale ressaltar que em resultados e discussão a ordem de apresentação dos dados obtidos segue a seguinte estruturação: 1) Segurança pública; 2) Abastecimento de água; 3) Disposição de efluente; 4) Limpeza pública; Pavimentação das vias.

\section{Resultados e Discussão}

\subsection{Quanto à Segurança Pública}

Para o indicador ambiental Segurança Pública, os dados obtidos e analisados indicaram que o núcleo CN obteve índice parcial de 0,42 , enquanto o núcleo NM alcançou 0,29, cuja divergência foi equivaleu a $13 \%$ entre os valores obtidos (Tabela 5).

Tabela 5: valores obtidos para o indicador Segurança Pública, Marabá, sudeste do Pará.

\begin{tabular}{cccc}
\hline & \multicolumn{3}{c}{ Segurança pública } \\
\hline Núcleo & Média & Índice parcial (Ip) & Índice total (Ip*peso) \\
Nova Marabá & 2,87 & 0,29 & 5,74 \\
Cidade Nova & 4,24 & 0,42 & 8,48 \\
\hline
\end{tabular}

Fonte: Autores (2018).

Essa discrepância pode ser explicada a partir do contexto populacional do Núcleo Cidade Nova (CN), já que foi observado que ela contratou segurança particular para o bairro Novo Horizonte, ao contrário da Nova Marabá (NM) que os moradores não dispõem deste serviço. Embora os valores para ambos os núcleos sejam muito baixos, a qualidade deste serviço no núcleo $\mathrm{CN}$ é superior em comparação com NM, o que não significa qualidade ambiental urbana por serem índices mínimos.

Nos estudos efetuados por Carvalho e Silva (2011), em Florianópolis - SC, e Lima et al. (2016), em São Paulo - SP, os autores concluíram que o sistema de segurança pública é um conjunto de ações delineadas em planos e programas como forma de garantir a segurança do indivíduo e não mostrou eficiente. Em Marabá, os dados obtidos corroboraram com os 
estudos realizados naqueles dois estados porque indicaram que este conjunto de ações foi qualificado como "ineficiente" a partir dos dados encontrados $(\mathrm{CN}=0,42 ; \mathrm{NM}=0,29)$. Em virtude disso, a qualidade do serviço público prestado é precária, o que acarreta o aumento da criminalidade para ambos os núcleos.

\subsection{Quanto ao abastecimento de água}

Quanto a esse indicador, os dados obtidos e analisados indicaram que, os núcleos estudados apresentaram valores distintos ( $\mathrm{NM}=0,52$ e $\mathrm{CN}=0,68)$, cuja divergência é de $16 \%$, entre os valores obtidos (Tabela 6).

Tabela 6: valores obtidos para o indicador Abastecimento de água, Marabá, sudeste do Pará.

\begin{tabular}{cccc}
\hline \multicolumn{4}{c}{ Abastecimento de água } \\
\hline Núcleo & Média & $\begin{array}{c}\text { Índice parcial } \\
\text { (Ip) }\end{array}$ & $\begin{array}{c}\text { Índice total } \\
\text { (Ip*peso) }\end{array}$ \\
Nova Marabá & 5,18 & 0,52 & 12,95 \\
Cidade Nova & 6,75 & 0,68 & 16,88 \\
\hline
\end{tabular}

Fonte: Autores (2018).

Tal discordância pode ser atribuída pela presença de planejamento urbano no núcleo $\mathrm{CN}$, e ausência na NM. Em pesquisa realizada por Encalada et al. (2016), no México, indicou que a influência das ações antrópicas sob a disponibilidade de água superficial, a qual avalia como uma problemática para o abastecimento de água. Já no estuo efetuado por Viana et al. (2020), na microbacia Tarumã, no Mato Grosso do Sul, os autores afirmaram que os corpos hídricos do Alto Rio Paraná, foram afetados com a expansão de crescimento populacional e o escoamento de resíduos urbanos, especialmente naqueles que funcionam como "mananciais".

Em contrapartida, no estudo feito em Marabá-PA, no núcleo NM, a problemática encontrada está no sistema de abastecimento, pois os moradores relatam interrupção no fornecimento de água periodicamente, o que reflete diretamente na qualidade deste indicador $(\mathrm{NM}=0,52)$. Em virtude disso, fazem uso de captação de água superficial, através de poço raso. Quanto ao núcleo $\mathrm{CN}$, não padece de tal problema, refletindo em um melhor índice $(\mathrm{CN}=0,68)$.

No estudo feito por Silva et al. (2016), no município de Jaboticabal - SP, concluíram que, embora as concessionárias apresentem tratamento adequado, os consumidores devem realizar periodicamente a limpeza dos reservatórios para preservação da qualidade da água que chega à residência. Diante disso, em pesquisa realizada no núcleo CN, bairro Novo Horizonte, concluiu-se que a qualidade da água oferecida aos moradores é boa, contudo, sofrem com a má gestão das redes distribuidores, como vazamentos que ocorrem nas redes de distribuição da concessionária (COSANPA), o que ocasiona a falta de água para a população.

\subsection{Quanto a Disposição de Efluente}

Quanto ao indicador ambiental Disposição de Efluente, os dados obtidos e analisados indicaram que, o núcleo CN obteve índice parcial equivalente a 0,40, enquanto o núcleo NM alcançou 0,32, cuja divergência entre ambos é de $8 \%$ (Tabela 7). 
Tabela 7: valores obtidos para o indicador Disposição de Efluente. Marabá, sudeste do Pará.

\begin{tabular}{cccc}
\hline \multicolumn{4}{c}{ Pavimentação das vias } \\
\hline Núcleo & Média & $\begin{array}{c}\text { Índice parcial } \\
\text { (Ip) }\end{array}$ & $\begin{array}{c}\text { Índice total } \\
\text { (Ip*peso) }\end{array}$ \\
Nova marabá & 4,87 & 0,49 & 7,31 \\
Cidade nova & 8,00 & 0,80 & 12,00 \\
\hline
\end{tabular}

Fonte: Autores (2018).

Esse percentual de discrepância é baixo em virtude de ambos os núcleos não atenderem a disposição final ambientalmente adequada, para o efluente gerado. Todavia, a qualidade deste serviço no núcleo CN é superior em comparação com NM. Em estudo efetuado por Nagali e Nemes (2009), em Curitiba-PR, os autores concluíram que os problemas da má disposição dos efluentes, alteram os padrões de qualidade da água. Em Marabá-PA, os valores encontrados para qualidade ambiental da disposição de efluente, confirmam o estudo em tela, o qual demonstram baixos índices para este indicador $(\mathrm{CN}=$ 0,40; NM= 0,32). Quanto ao núcleo NM, a população da Folha 22, em sua maioria, afirma possuir o básico sistema de fossa séptica, no entanto, quanto ao efluente gerado pelo uso da água em atividades do cotidiano, estes não possuem nenhum sistema de tratamento. No que se refere a estação de tratamento de efluente (ETE) do núcleo, este não a possui.

Pesquisa realizada por Victorette e Brentano (2010), em Santa Catarina - SC, indicou que o despejo de efluente doméstico sem tratamento aumenta a DBO em corpos hídricos, o qual pode provocar a eutrofização do corpo receptor. Em Marabá-PA, os dados obtidos ratificam esta pesquisa, dado que no núcleo $\mathrm{CN}$, pode-se observar que as residências possuem fossa séptica, bem como, a prefeitura disponibiliza rede de tratamento de esgoto, no entanto, a população não se adequa a este, pois, relataram que o gasto para inserir a residência no sistema é elevado e inviável. Desse modo, todo esgoto é lançado a rede coletora pluvial e exposto diretamente em vias públicas.

\subsection{Quanto a Limpeza Pública}

Para o indicador ambiental Limpeza Pública, os dados obtidos e analisados indicaram que, os núcleos estudados apresentaram valores próximos de índice parcial $(\mathrm{NV}=0,77$ e $\mathrm{CN}=0,79)$, esta diferença mínima (2\%), entre ambos (Tabela 8).

Tabela 8: valores obtidos para o indicador Limpeza Pública, Marabá, sudeste do Pará.

\begin{tabular}{cccc}
\hline \multicolumn{4}{c}{ Limpeza pública } \\
\hline Núcleo & Média & Índice parcial (Ip) & $\begin{array}{c}\text { Índice total } \\
\text { (Ip*peso) }\end{array}$ \\
Nova Marabá & 7,74 & 0,77 & 15,48 \\
Cidade Nova & 7,93 & 0,79 & 15,86 \\
\hline
\end{tabular}

Fonte: Autores (2018).

Pode ser explicada, pela interligação entre a coleta seletiva/limpeza pública, e a qualidade da pavimentação do bairro $(\mathrm{CN}=0,80$ e NM = 0,49) (Tabela 8). Uma vez que, o caminhão coletor não visita as ruas de difícil acesso, ou seja, ruas sem pavimentação, que apresentem crateras, ou fissuras. Ainda assim, a qualidade deste serviço em ambos os núcleos é similar, apesar da influência da qualidade da pavimentação nesse indicador. 
Estudo efetuado por Saika e Nath (2015), na cidade de Tezpur na Índia, conclui que dentre os fatores que afetam a qualidade da limpeza pública estão as questões financeiras e a falta de coordenação e cooperação entre as autoridades e o público. Em contrapartida, foi observado na área de estudo desta pesquisa, uma melhoria na qualidade desse serviço em ambos os núcleos, o que proporcionou uma semelhança/paridade nos índices encontrados ( $\mathrm{CN}=0,79$ e $\mathrm{NM}=0,77)$, devido o maior investimento público nessa área. Ressalta-se também que a participação da comunidade no sistema de limpeza pública tem que ser efetuada, para o bom gerenciamento deste.

Em pesquisa realizada por Fürstenau e Fofonka (2012), demostram que as cidades europeias contam com um bom serviço de limpeza urbana, e que recebe bastante atenção no orçamento municipal e comprometimento da população. $\mathrm{Na}$ pesquisa feita em Marabá-PA, o índice dos núcleos analisados demonstra boa qualidade do sistema de coleta $(0,77$ e 0,79$)$. Embora o sistema de limpeza pública dos núcleos tenha suprido as necessidades da população, alguns indivíduos não possuem conceitos de disposição adequada dos resíduos gerados, o que dificulta a coleta deste.

\subsection{Quanto a Pavimentação das Vias}

Para o indicador ambiental Pavimentação das vias, os dados obtidos e analisados indicaram que, no núcleo CN obteve índice parcial de 0,80 , em contrapartida no núcleo NM alcançou 0,49, cuja divergência é de $31 \%$ entre os valores obtidos (Tabela 9).

Tabela 9: valores obtidos para o indicador Pavimentação das vias, Marabá, sudeste do Pará.

\begin{tabular}{cccc}
\hline \multicolumn{3}{c}{ Pavimentação das vias } \\
\hline Núcleo & Média & Índice parcial & Índice total (Ip*peso) \\
Nova marabá & 4,87 & $(I p)$ & 7,31 \\
Cidade nova & 8,00 & 0,49 & 12,00 \\
& & 0,80 & \\
\hline
\end{tabular}

Fonte: Autores (2018).

A diferença entre os valores encontrados justifica a ausência e/ou a péssima qualidade de asfalto encontrado no núcleo Nova Marabá, em virtude do mau planejamento deste. Estes índices indicam que, a qualidade do serviço no núcleo CN é superior em comparação com NM.

Em pesquisa realizada por Lima et al. (2016), em Salvador - BA, e Rodríguez et al. (2016), no Chile, indicaram que a pavimentação das vias e fator determinante para a melhoria da qualidade de vida, bem como, reflete diretamente na valorização de imóveis em áreas urbanizadas. Em Marabá-PA, os valores encontrados quanto aos índices parciais deste indicador corroboram esta pesquisa, dado que o índice da $\mathrm{CN}$ e $\mathrm{NM}(\mathrm{CN}=0,80$ e $\mathrm{NM}=0,49)$ refletem a realidade dos moradores dos núcleos onde o de maior valor possui melhor qualidade das vias, e o de pior valor carece de melhorias na pavimentação.

Em estudo efetuado por Quintana et al. (2016), em Bogotá - COL, os autores concluíram que fatores climáticos (aumento de umidade) implicam na deterioração do asfalto. Em Marabá-PA, isso também foi observado quanto a análise do índice da NM, pois, além da precária qualidade do asfalto encontrado, há ruas que ainda não foram asfaltadas, fator este que torna o solo mais exposto a ações intempéries. Ademais, há também, ruas com pavimentação em broquetes, que não possuem qualidade satisfatória para a passagem de veículos. 


\subsection{Quanto ao IQAU dos núcleos}

Para o Índice de Qualidade Ambiental Urbano, os dados obtidos e analisados indicaram que, os núcleos estudados apresentaram valores distintos, onde o núcleo Nova Marabá alcançou um IQAU de 47,96, enquanto o núcleo Cidade Nova obteve 63,17, cuja divergência é de 15,21\%, entre os valores obtidos (Tabela 10). Essa diferença entre os valores encontrados é explicada pelo planejamento encontrado em cada núcleo, isso indica que, a qualidade de vida da população do núcleo CN é superior ao da NM.

Tabela 10: valores obtidos para o indicador Distribuição de água, Marabá, sudeste do Pará.

\begin{tabular}{lr}
\hline \multicolumn{2}{c}{ Índice de Qualidade Ambiental } \\
\hline Núcleo & \\
IQAU \\
Nova Marabá & 47,96 \\
Cidade Nova & 63,17 \\
\hline Fonte: Autores (2018).
\end{tabular}

Fonte: Autores (2018).

Segundo Dias e Gomes (2011), em Cuiabá - MT, a IQAU encontrada nos núcleos se classificam como intermediário (CN) e ruim (NM), fator este determinado pela carência do planejamento, o que reflete sob os indicadores adotados no estudo. Para o núcleo CN o IQAU classifica-se como intermediário $(63,17)$, embora seja superior ao núcleo NM, este possui indicadores com qualidade ambiental urbana boa (Limpeza pública-0,79; pavimentação-0,80). No entanto, ainda se faz necessário melhorias na infraestrutura do núcleo, no que se refere aos indicadores de menor índices (Segurança pública-0,42; disposição e afastamento de efluentes-0,40).

Em pesquisa realizada por Pereira Júnior et al. (2017), em Marabá - PA, os autores indicaram um IQA para o núcleo NM de 43,60, classificado segundo Dias et al. (2011), como ruim. Nesse sentido, a pesquisa efetuada na Folha 22 do núcleo NM, obteve um IQAU correspondente a 47,96. Esta pequena diferença encontrada entre ambas as pesquisas $(4,36)$, pode ser atribuída a metodologia aplicada no que tange a quantidade de indicadores ambientais utilizados. Desse modo, verificou-se que o melhor indicador encontrado no núcleo NM foi o de limpeza pública $(0,77)$. Ademais, os indicadores de maior carência, foram os de segurança pública $(0,29)$ e disposição e afastamento de efluentes $(0,32)$, os quais influenciaram negativamente no IQAU.

Nos dois estudos realizados por Lima (2013), nas cidades de Epitácio - SP, e Nova Andradina - MS, os autores concluíram que para melhor compreender e avaliar a qualidade ambiental em sua complexidade, consiste em analisar os indicadores que os representavam melhor, bem como, a atribuição de pesos, ou seja, da quantificação de indicadores ambientais selecionados para a realidade da cidade. Nesse estudo isso foi empregado e as representações mostraram-se eficazes para a construção do IQAU

\section{Sugestões}

Para os núcleos CN e NM, o indicador ambiental segurança pública merece maior atenção, visto que obteve índices muito baixo, como medida mitigadora deste impacto, deve-se haver adoção de um aumento da frota de policiamento local, bem como, a patrulha das viaturas em vias de menor movimentação. 
Quanto a limpeza pública, ambos os bairros apresentam um índice bom, contudo, notou-se que este indicador ainda pode melhorar, através do envolvimento da população. Com isso, sugere-se que seja realizado programas de educação ambiental, no intuito de informar a comunidade quanto aos horários, e os dias em que será realizada a coleta dos resíduos em cada área de estudo (CN e NM), para que assim, a população faça a disposição dos seus resíduos nos locais adequados, bem como, em horários próximos a coleta, de modo a evitar o acúmulo deles nas vias, com o intuito de evitar tanto a atração de vetores, quanto a poluição visual.

Sob o mesmo ponto de vista, outra medida que pode ser adotada, é o estabelecimento de um sistema de gestão de resíduos sólidos urbanos eficiente e apropriado para a cidade, com o acerto de políticas públicas voltadas para o manejo adequado destes, a fim de suprir as reais necessidades da cidade, com o objetivo de evitar sérias consequências sociais, de saúde pública e no meio ambiente.

A vista disso, outro indicador de baixo índice encontrado que afeta diretamente na qualidade ambiental urbana da população foi a distribuição de efluentes gerados, no qual o núcleo $\mathrm{CN}$, apesar de possuir rede de tratamento a população não aderiu a inserção do sistema. Dessa forma, faz-se necessário a divulgação deste sistema, assim como, as vantagens que este serviço trará para a população. Por outro lado, no núcleo NM, não possui qualquer tipo de tratamento posterior da rede de esgoto, assim, como medida deve-se implantar uma estação de tratamento de esgoto (ETE), cujo dimensionamento supra as necessidades do núcleo como um todo.

A respeito do indicador abastecimento de água, observou-se que os núcleos estudados apresentam como problemática, a falta periódica de água, em virtude da má gestão das redes distribuidores. Por essa razão, sugere-se que a concessionária invista no monitoramento e gerenciamento do sistema de abastecimento, a fim de evitar futuros vazamentos e problemas adversos (falta do recurso hídrico, alteração da qualidade da água, vazamentos no sistema da rede).

Por outro lado, o indicador ambiental pavimentação das vias no núcleo $\mathrm{CN}$, bairro Novo Horizonte, possui índice bom, a vista disso, como medida para aumentar a qualidade do serviço prestado pela prefeitura, deve-se realizar a manutenção do asfalto em alguns pontos do núcleo. Em contrapartida, o núcleo NM, em sua maioria não possui asfalto, o que torna este indicador com baixa qualidade, desse modo, faz-se necessário a pavimentação das vias, ou a colocação de broquetes nas vias de menor trânsito de veículos, a fim de melhorar a qualidade deste indicador no núcleo.

\section{Conclusão}

A aplicação do método de avalição de impacto da qualidade ambiental urbana, por intermédio da utilização da Matriz de Leopoldo e adoção de indicadores ambientais foi satisfatória, pois, refletiu as problemáticas ambientais encontradas em ambos os núcleos de estudo. Com isso, a construção do Índice de Qualidade Ambiental Urbana permitiu indicar que o núcleo $\mathrm{CN}$ possui melhor qualidade ambiental que o núcleo NM, pois a percepção ambiental dos moradores indicou contraposições em ambos os núcleos. Assim, o núcleo Cidade Nova, destaca-se por ter planejamento urbano, o que contrapõe as características observadas na Nova Marabá, visto que esta apresenta características de invasão e má alocação da população.

A vista disso, embora alguns índices (pavimentação, limpeza pública) tenham sido de boa qualidade ambiental para os bairros, fez-se necessário propor medidas que mitiguem os impactos negativos encontrados, bem como, potencializem os indicadores que apresentaram bons índices. Desse modo, proporcionam melhorias no Índice de Qualidade Ambiental Urbana. Sugere-se que haja monitoramento constante por parte dos gestores municipais quanto a esses índices com estudos semestrais e que possibilitem uma comparação entre os dados obtidos e os aqui publicados para realização de um banco de dados úteis aos vereadores desse município, quando da elaboração de políticas ambientais que promovam a conservação ambiental e mantenham a qualidade de vida urbana dos munícipes. 


\section{Referências}

Adão, N. M. L., \& Polette, M. (2016). Sistema de Indicadores de Qualidade Ambiental Urbana para Metrópoles Costeiras (SIMeC): uma proposta de instrumento de análise territorial. Estudos Urbanos Regionais, 18(2),325-342. https://rbeur.anpur.org.br/rbeur/article/view/5157 Doi: https://dx.doi.org/10.22296/2317-1529.2016v18n2p325

Belizário, W. S. (2014). Impactos ambientais decorrentes da expansão urbana no córrego Pipa em aparecida de Goiânia, Goiás. Mirante, 7(2), 58-77. https://www.revista.ueg.br/index.php/mirante/article/view/3173

Carvalho, J. R. M., \& Curi, W. F. (2013). Construção de um índice de sustentabilidade hidro ambiental através de análise multicritério: estudo em municípios paraibanos. Sociedade e Natureza, 25(1), 91-106. https://www.scielo.br/j/sn/a/CTNVMSRwWsY5vwhG7WPvkWC/?format=pdf\&lang=pt Doi: https://dx.doi.org/10.1590/S1192-45132013000100008

Carvalho, V. A., \& Silva, M. R. F. (2011). Política de segurança pública no Brasil: avanços, limites e desafios. Revista Ktálysis, 14(1),59-67, 2011 https://periodicos.ufsc.br/index.php/katalysis/issue/view/1626

Cavalcante, L. G. \& Leite, A. O. S. (2016). Aplicação da Matriz de Leopold como ferramenta de avaliação dos aspectos e impactos ambientais em uma fábrica de botijões. Revista Tecnológica, 37(1), 111-124. https://periodicos.unifor.br/tec/article/view/5698

Doi: https://dx.doi.org/10.5020/23180730.2016.V37.1/2.111-124

Dias, F. A., Gomes, L. A., \& Alkmim, J. K. (2011). Avaliação da qualidade ambiental urbana da Bacia do Ribeirão do Lipa através de indicadores, Cuiabá/MT. Revista Sociedade \& Natureza, 23(1),127-147. http://www.seer.ufu.br/index.php/sociedadenatureza/article/view/11389

Encalada, J. A. D., Caceres, A. P., Bandala, E. R., \& Wright, G. H. (2016). The impact of global climate change on water quantity and quality: A system dynamics approach to the US-Mexican transborder region. European Journal of Operational Research, 256(2), 567-581, doi: https://dx.doi.org/10.1016/j.ejor.2016.06.016

Ferreira, P. F. M., \& Matias, L. F. (2011). Mapeamento e análise dos impactos socioambientais urbanos em Itacaré (Ba), Brasil. Geográfica de América Central, 1-15. https://www.ige.unicamp.br/geoget/acervo/artigos/mapeamento\%20e\%20analise\%20Paula.pdf

Fornazieiro, M. P. A. (2020). Qualidade Ambiental Urbana: proposta de um índice para a cidade de Rio Claro/SP. Dissertação (Mestrado em Geografia) Universidade Paulista "Júlio de Mesquita Filho", São Paulo, 2020. https://repositorio.unesp.br/handle/11449/202353\#: :text=A\% 20qualidade $\% 20$ ambiental\%20urbana $\% 20 \% \mathrm{C} 3 \%$ A 9 ,qualidade $\% 20 \mathrm{de} \% 20$ vida $\% 20 \mathrm{da} \% 20$ popula $\% \mathrm{C} 3 \% \mathrm{~A} 7 \% \mathrm{C} 3 \% \mathrm{~A} 3 \mathrm{o} . \&$ text $=\mathrm{Como} \% 20 \mathrm{resultado} \% 2 \mathrm{C} \% 20$ foi $\% 20$ gerada\%20a,\%2C32\%20e\%204\%2C95

Fürstenau, B. B. R. J., \& Fofonka, L. (2012). Limpeza urbana e manejo de resíduos sólidos: as impressões ao observar espaços urbanos em duas cidades brasileiras e seis capitais europeias. Educação ambiental em ação, (39), https://www.revistaea.org/artigo.php?idartigo=1213

Gonçalves, L.F.H., \& Guerra, A. J. T. (2009). Movimentos de massa na cidade de Petrópolis (RJ). In: Guerra, A.J.T., \& Cunha, S.B.C. (Org.). Impactos ambientais urbanos no Brasil. Rio de Janeiro: Bertrand Brasil.

Kemerich, P. D. C., Ritter, L. G., \& Borba, W. F. (2014). Indicadores de sustentabilidade ambiental: métodos e aplicações. Revista Monografias Ambientais, 3(5),3723-3736. https://periodicos.ufsm.br/remoa/article/view/14411, doi: https://dx.doi.org/10.5902/2236130 814411

Lei n. 10.257, de 10 de julho de 2001. Regulamenta arts. 182 e 183 da Constituição Federal, estabelece diretrizes gerais da Política Urbana e da outras providencias. http://www.planalto.gov.br/ccivil_03/LEIS/LEIS_2001/110257.htm

Lei $n .^{\circ} 11.445$ de 5 de janeiro de 2007. Estabelece as diretrizes nacionais para o saneamento básico; cria o Comitê Interministerial de Saneamento Básico; altera as Leis ${ }^{\text {os }} 6.766$, de 19 de dezembro de 1979, 8.666, de 21 de junho de 1993, e 8.987, de 13 de fevereiro de 1995 ; e revoga a Lei ${ }^{\circ}$ 6.528, de 11 de maio de 1978. http://www.planalto.gov.br/ccivil_03/_ato2007-2010/2007/lei/111445.htm

Lei $n^{\circ}$ 12.305, de 2 de agosto de 2010. Institui a Política Nacional de Resíduos Sólidos, altera a lei n. ${ }^{\circ} 9.605$, de 12 de fevereiro de 1998 , e dá outras providências. http://www.planalto.gov.br/ccivil_03/_ato2007-2010/2010/lei/112305.htm

Lima, A. C. M., Fernandes, L. ., Lopes, D, F., Bittencourt, F, M.., Vinagre, M. A. A., \& Silva, E. M., (2020) Urbanização e canais urbanos: avaliação da qualidade das águas da bacia hidrográfica do Uma no município de Belém, Brasil. Research, Society and Development, 9(7),1-23. https://rsdjournal.org/index.php/rsd/article/view/3866, doi: https://dx.doi.org/10.33448/rsd-v9i7.3866

Lima, S. R., Bueno, S., \& Mingardi, G. (2016). Estado, polícias e segurança pública no Brasil. Escola de Direito de São Paulo, 12(1), 49-85. http://bibliotecadigital.fgv.br/ojs/index.php/revdireitogv/article/view/59454/57846

Lima, V. (2013). A sociedade e a natureza na paisagem urbana: análise de indicadores para avaliar a qualidade ambiental. Tese (Doutorado). Universidade Estadual Paulista Júlio de Mesquita Filho, Faculdade de Ciências e Tecnologia, 2013. http://www2.fct.unesp.br/pos/geo/dis_teses/13/dr/valeria.pdf, doi: https://dx.doi.org/10.48075/geoq.v7i2.9385

Lima, V. (2014). Análise da qualidade ambiental urbana: o exemplo de Osvaldo Cruz/SP. Geografia em questão, 7(2),29-46. http://erevista.unioeste.br/index.php/geoemquestao/article/view/9385

Matias Pereira, J. (2016). Manual de Metodologia da Pesquisa Científica. (4 ed.). Atlas.

MICROSOFT (2013). Project for Windows 10. Version 4.1. [S.I]: Microsoft Corporation, 2013. 1 CD-ROM.

Miranda, L. H., Morato, R. G., \& Kawakubo, F. S. (2012). Mapeamento da qualidade de vida urbana em Pouso Alegre, Sul de Minas Gerais. Revista do Departamento de Geografia, 24, p. 24-36, 2012. https://www.revistas.usp.br/rdg/article/view/52752, DOI: https://dx.doi.org/10.7154/rdg.2012.0024.002 
Nagalli, A., \& Nemes, P. D. (2009). Estudo da qualidade de água de corpo receptor de efluentes líquidos industriais e domésticos. Ciências Agrárias e Ambientais, 7(2),131-144. https://periodicos.pucpr.br/index.php/cienciaanimal/article/view/9840, doi: https://dx.doi.org/10.7213/cienciaanimal.v7i2.9840

Norma Brasileira de Regulamentação $n^{\circ} 9.648$ de 30 de novembro de 1986. Fixa as condições exigíveis no estudo de concepção de sistemas de esgoto sanitário do tipo separador, com amplitude suficiente para permitir o desenvolvimento do projeto de todas ou qualquer das partes que o constituem, observada a regulamentação específica das entidades responsáveis pelo planejamento e desenvolvimento do sistema de esgoto sanitário https://www.abntcatalogo.com.br/norma.aspx?ID=079679

Pechincha, M. G. H., \& Zaidan, R. T. Análise da qualidade ambiental urbana através de ambiente SIG: uma aplicação no município de Juiz de Fora - MG. Revista Brasileira de Cartografia, 68(2), 355-371. http://www.seer.ufu.br/index.php/revistabrasileiracartografia/article/view/44400

Penereiro, J.C., \& Ferreira, D.H. (2012). A Modelagem Matemática Aplicada às Questões Ambientais: Uma Abordagem Didática no Estudo da Precipitação Pluviométrica e da Vazão de Rios. Millenium, 2(5) 27-47. https://dialnet.unirioja.es/servlet/articulo?codigo=4046937

Pereira, A. S., Shitsuka, D. M., Parreira, F. J., \& Shitsuka, R. (2018). Metodologia da pesquisa cientifica. Santa Maria: UFSM.

Pereira Júnior, A., Oliveira, G. P., Nicácio, J. A., Farias, L. J., \& Costa, S. T. L. (2017). Modelo matemático para avaliação da qualidade ambiental: o caso dos núcleos Marabá Pioneira e Nova Marabá, Marabá - Pa. Gestão e Sustentabilidade Ambiental, 6(3),405-423. http://www.portaldeperiodicos.unisul.br/index.php/gestao_ambiental/article/view/5573, doi: https://dx.doi.org/10.19177/rgsa.v6e32017405-423

Polette, M., \& Lins-De-Barros, F. (2012). Os desafios urbanos na zona costeira brasileira frente as mudanças climáticas. Costas Revista Ibero-americana de Manejo Costeiro Integrado, 1(1),165-180. http://www.cona.cl/noticias/2012/0020costas/Costas-Vol1.pdf\#page=171

Pontes; L. B., \& Cardoso; A. C. D. (2016). Open Spaces: windows for ecological urbanism in the Eastern Amazon. Brazilian Journal of Urban Management. Gestão Urbana, 8(1),96-112. https://www.scielo.br/j/urbe/a/HjpypdVGBvRdWhQcBTX3XTR/?format=pdf\&lang=en,

Portaria $n^{\circ} 2.914$ de 12 de dezembro de 2011. Dispõe sobre os procedimentos de controle e de vigilância da qualidade da água para o consumo humano e seu padrão de potabilidade. http://site.sabesp.com.br/uploads/file/asabesp_doctos/kit_arsesp_portaria2914.pdf

Quintana, H. A. R., Ruge, J. C. C., \& Anselmi, L. A. M. (2016). Efecto del agua sobre el asfalto y su posible influencia en el daño por humedad en una mezcla asfáltica porosa. Ingeniare, Revista Chilena 24(4),558-569. https://www.ingeniare.cl/index.php?option=com_ingeniare\&view=vv\&vid=109\&lang=es, doi: https://dx.doi.org/10.4067/S0718-33052016000400003

Resolução CONAMA n. 357 de 17 de março de 2005. Dispõe sobre a classificação dos corpos de água e diretrizes ambientais para o seu enquadramento, bem como estabelece as condições e padrões de lançamento de efluentes e dá outras providências. http://www2.mma.gov.br/port/conama/legiabre.cfm?codlegi=459

Resolução CONAMA N. ${ }^{\circ} 430$ de 13 de maio de 2011 Dispõe sobre as condições e padrões de lançamentos de efluentes, contempla e altera a Resolução 357, de 17 de março de 2005, do Conselho Nacional do Meio Ambiente - CONAMA. http://www2.mma.gov.br/port/conama/legiabre.cfm?codlegi=646

Resolução n. 466 de 12 de dezembro de 2012. Diretrizes e normas regulamentadoras de pesquisa envolvendo seres humanos. https://conselho.saude.gov.br/resolucoes/2012/Reso4

Resolução n. 512 de 5 de maio de 2016. Altera a Resolução n. 466 , de 12 de dezembro de 2012, e dá outras providências. https://www.in.gov.br/materia//asset_publisher/Kujrw0TZC2Mb/content/id/22809170/do1-2016-05-13-resol.

Rocha, J. S. M., Garcia, S. M., \& Ataides, P. R. V. Manual de avaliações de impactos e passivos ambientais. Santa Maria: Palloti, 2005

Rodrigues, J. P. (2013). Modelagem matemática da dispersão aplicada à definição de locais para o monitoramento da qualidade do ar. Monografia (Trabalho de Conclusão de Curso (Tecnologia em Processos Ambientais). Universidade Tecnológica Federal do Paraná., Paraná. https://repositorio.utfpr.edu.br/jspui/handle/1/9650

Rodríguez, M., Thenoux, G., \& González, A. (2016). Determinación probabilística del tiempo de servicio de Estructuras de Pavimentos. Ingeniería de Construcción, 31(2),83-90. https://revistaschilenas.uchile.cl/handle/2250/82459, doi: https://dx.doi.org/10.4067/S0718-50720160002200002

Saikia, D., \& Nath, M. J. (2015). Integrated solid waste management model for developing country with special reference to Tezpur municipal area, India. International Journal of Innovative Research \& \& $\quad$ Development, 241-249. http://internationaljournalcorner.com/index.php/ijird_ojs/article/view/135378/94503

Sakamoto, C. K; \& Silveira, I. O. (2014). Como fazer projetos de iniciação científica. São Paulo: Paulus, 2014.

Sánchez, L. H. (2013). Avaliação de Impacto Ambiental. (2ª ed. rev. e ampl.) São Paulo: Oficina de Textos.

Silva, L. J.; Lopes, L. G.; Amaral, L. A. (2016). Qualidade da água de abastecimento público do municio de Jaboticabal, SP. Engenharia Sanitária Ambiental, 21(3),615-622. https://www.scielo.br/j/esa/a/3MnPrXHDSGQbWgcQ6Q9DyFK/?lang=pt, doi: https://dx.doi.org/10.1590/S1413-41522016121151

Sousa, M. N. A., Viera, T. G., Barbosa, A. L. L., Souza, K. C., Araújo, L. V. P. N., Lima, M. T. P., \& Bezerra, A. L. D. (2016). Estresse, qualidade de vida e trabalho: estudo com agentes da limpeza urbana. Revista Brasileira de Qualidade de Vida, 8(4), 281-295. https://periodicos.utfpr.edu.br/rbqv/article/view/4846, doi: https://dx.doi.org/10.3895/rbqv.v8n4.4846

Souza, J. R., Moraes, M. E. B., Sonoda, S. L., \& Santos, Hallala C. R. G. (2014). A importância da qualidade da água e os seus múltiplos usos: Caso Rio Almada, Sul da Bahia, Brasil. Revista Eletrônica do Prodema, 8(1),26-45 http://www.revistarede.ufc.br/rede/article/view/217

Souza Filho J, S., Abreu, B. M. S., Albuquerque, F. R., Melo, E. S. R. L., \& Santos, A. F. M. S. Estudo de caso: disposição dos efluentes sanitários brutos no solo associados a falhas no sistema sanitário municipal. In: Congresso Internacional de Ciências Agrárias. 3. 2018. Anais eletrônicos https://cointerpdvagro.com.br/wp-content/uploads/2019/02/ESTUDO-DE-CASO-DISPOSI\%C3\%87\%C3\%83O-DE-EFLUENTES-SANIT\%C3\%81RIOS-BRUTOS-NO- 
Research, Society and Development, v. 10, n. 10, e510101019142, 2021

(CC BY 4.0) | ISSN 2525-3409 | DOI: http://dx.doi.org/10.33448/rsd-v10i10.19142

SOLO-ASSOCIADOS-A-FALHAS-NO-SISTEMA-SANIT\%C3\%81RIO-MUNICIPAL.pdf,

doi:

https://dx.doi.org/10.31692/25267701.IIICOINTERPDVAGRO.2018.00481

Teixeira, A. S., Jesus. E. S., \& Pereira Júnior, A. (2019). Avaliação da qualidade ambiental urbana no município de Altamira, Pará. Revista Cientifica Multidisciplinar Núcleo do Conhecimento, 4(10),54-57. https://www.nucleodoconhecimento.com.br/engenharia-ambiental/qualidadeambiental\#: : text=O\%20valor\%20obtido\%20para\%20o\%20IQAU\%2C\%20foi\%20igual\%20a\%2036,Independente\%20I\%2C\%20Altamira\%20\%E2\%80\%93 \%20PA.\&text=Fonte\%3A\%20autores\%20(2016).,-Estudo\%20fetuado\%20na, doi: https://dx/doi.org/10.32749/nucleodoconhecimento.com.br/engenhariaambiental/qualidade-ambiental

Valesí, R. H. (2014). A contribuição do estudo do impacto de vizinhança como processo de transformação do direito de propriedade. Revista Faculdade de Direito, (2), 162-179 https://revistadireito.emnuvens.com.br/revistadireito/article/view/26

Viana, L. F., Francisco, L. F. V., Cardoso, C. A. L., Solórzano, J, C., \& Lima-Júnior, S. E. (2020) Avaliação do índice de vegetação e da concentração de metais em sedimentos na microbacia Tarumã, Mato Grosso do Sul, Brasil. Research, Society and Development, 9(7), 1-16. https://rsdjournal.org/index.php/rsd/article/view/4862/4230, doi: https://dx.doi.org/10.33448/rsd-v9i7.4862

Victorette, T. W. D. B., \& Brentano, D. M. (2010). Qualidade da água da bacia Hidrográfica do Rio Ratones, Florianópolis/SC, nas estações de primavera e verão. Pensar Ciência, 3(1), 44-52. https://periodicos.ifsc.edu.br/index.php/publicacoes/article/view/91 